\title{
Modern Trends in Early Diagnosis of Acute Respiratory Distress Syndrome
}

\section{Kuzovlev AN*}

V.A. Negovsky scientific research institute of general reanimatology RAMS, Moscow, Russia

Acute respiratory distress syndrome (ARDS) is a noncardiogenic pulmonary edema, in the basis of which lies an alteration (dystrophy, necrosis, apoptosis) of alveolar epithelium, pulmonary microcirculation endothelium, and their basal membranes (including structures of aerohematic barrier) by endogenous and exogenous aggressive factors, leading to vascular permeability growth and development of acute respiratory failure $[1,2]$

For many years since its first description in 1967 [3] ARDS has remained a critical condition with a high morbidity and mortality [4], which is in great deal due to an inability of the currently used clinical ARDS criteria to detect the early stage of the syndrome. The problem of prompt diagnosis is of great significance for critical care medicine: the earlier we diagnose the critical condition, the broader spectrum of treatment approaches we have and the better are the outcomes.

Three diagnostic tools for ARDS are currently available: the Murray score [5], the American-European consensus conference criteria [6], the Delphi criteria [7]. The Murray score is not designed to differentiate between stages of ARDS and no data exist that this score correlates with outcomes [8]. The widely used American-European consensus conference criteria are based on oxygenation index and chest X-ray. Oxygenation index decrease is an important marker of ARDS, but is highly dependent on numerous clinical variables apart from ARDS (pneumonia, atelectasis, bronchial obstruction etc). The chest X-ray, especially made by a portable machine, is not informative for the diagnosis of early ARDS stage: bilateral pulmonary infiltrates are only detected at later stages $[1,2,9,10]$. The Delphi criteria, which take into account the influence of positive end-expiratory pressure on oxygenation index, did not win popularity among clinicians [7]. The recent definition of ARDS proposed at the 2011 ESICM Annual Congress deals not only with routine criteria, but also with the timing, physiological derangements and 3 degrees (mild, moderate and severe) of ARDS. This is a step forward for diagnosing an early ARDS stage. But none of the abovementioned criteria are based on the pathogenesis of the early ARDS stage.

Pathogenesis, diagnosis and treatment of ARDS have long been an area of interest for the scientists of the V.A. Negovsky scientific research institute of general reanimatology. A multicenter investigation (pathological, experimental, clinical) carried out at the V.A. Negovsky scientific research institute of general reanimatology in 2000-2011 confirmed that the non-cardiogenic pulmonary edema is the crucial element of the pathogenesis of early ARDS stage and a key for its detection in the clinical setting. Interstitial and alveolar pulmonary edema is seen within 2-3 hrs after the direct or indirect insult to the lung $[1,2,9,10]$. Therefore, signs of pulmonary edema should be the most reliable for diagnosing an early ARDS. Clinically the non-cardiogenic pulmonary edema can be reliably detected and dynamically monitored by the transpulmonary thermodilution using the extravascular lung water index (EVLWI), which was confirmed in an array of investigations [1,2,9-11].

The modern approach to diagnose an early ARDS stage based on the detection of non-cardiogenic pulmonary edema was developed at the V.A. Negovsky scientific research institute of general reanimatology (Table 1). These criteria provided clinicians with a possibility to diagnose early, reversible stage of ARDS and start prompt $t$ reatment which improves outcome. These complex strategies made it possible to decrease the duration of artificial pulmonary ventilation by 4-7 days, the intensive care unit stay by 5-6 days, the hospital stay by 10 days, the rate

\begin{tabular}{l}
\hline - Acute onset \\
- Extravascular lung water index $>7 \mathrm{ml} / \mathrm{kg}$ \\
\hline - Oxygenation index $<300 \mathrm{mmHg}$ \\
\hline - No left-ventricular insufficiency \\
\hline No signs of ARDS in direct chest X-ray
\end{tabular}

Table 1: Early ARDS stage new diagnostic criteria, developed at the V.A. Negovsky scientific research institute of general reanimatology [1-2].

of pulmonary complications by $31,9 \%$, the price of treatment per patient by 130,000 RUB and the mortality- by $29,6 \%[1,2,9,10]$.

Therefore, the diagnostic algorithms in critical care medicine should be based on the pathogenesis of the critical state. The knowledge of the pathogenesis of the early ARDS stage made it possible to develop a modern diagnostic approach, which is effective and recommended to be implemented into a daily practice. Future research is focused on investigations into novel biomarkers of ARDS.

\section{References}

1. Moroz V, Goloubev A, Kuzovlev AN (2010) Acute respiratory distress syndrome: new classification. Semin Cardoiothorac Vasc Anesth 14: 46.

2. Moroz V, Goloubev (2007) A Classification of acute respiratory distress-syndrome. General Reanimatology 3: 7-9.

3. Ashbaugh DG, Bigelow DB, Petty TL, Levine BE (1967) Acute respiratoty distress in adults. Lancet 2: 319-323.

4. Lewandowski K, Lewandowski M (2006) Epidemiology of ARDS. Minerva Anestesiol 72: 473-477.

5. Murray JF, Matthay MA, Luce JM, Flick MR (1988) An expanded definition of the adult respiratory distress syndrome. Am Rev Respir Dis 138: 720-723.

6. Bernard GR, Artigas A, Brigham AM, Carlet J, Falke K, et al. (1994) The AmericanEuropean Consensus Conference on ARDS. Definitions, mechanisms, relevan outcomes, and clinical trial coordination. Am J Respir Crit Care Med 149: 818-824.

7. Ferguson ND, Davis AM, Slutsky AS, Stewart TE (2005) Development of a clinica definition for acute respiratory distress syndrome using the Delphi technique. J Crit Care 20: 147-154.

8. van der Heijden M, Groeneveld AB (2010) Extravascular lung water to blood volume ratios as measures of pulmonary capillary permeability in nonseptic critically ill patients. J Crit Care 25: 16-22.

9. Moroz VV, Goloubev AM (2006) Principles of early stages of acute lung injury diagnosis. General Reanimatology II: 5-7.

10. Kuzovlev AN, Moroz VV, Goloubev AM, Polovnikov SG (2010) Diagnosis of acute respiratory distress syndrome in nosocomial pneumonia. Semin Cardiothorac Vasc Anesth 14: 231-241.

11. Matthay M (2008) Measurement of extravascular lung water in patients with pulmonary edema. Am J Physiol Lung Cell Mol Physiol 294: 1021-1022.

*Corresponding author: Kuzovlev AN, MD, PhD, V.A. Negovsky scientific research institute of general reanimatology RAMS Moscow, Russia, E-mail: artem_kuzovlev@mail.ru

Received February 29, 2012; Accepted March 03, 2012; Published March 05 2012

Citation: Kuzovlev AN (2012) Modern Trends in Early Diagnosis of Acute Respiratory Distress Syndrome. J Pulmonar Respirat Med 2:e104. doi:10.4172/2161-105X.1000e104

Copyright: (C) 2012 Kuzovlev AN. This is an open-access article distributed unde the terms of the Creative Commons Attribution License, which permits unrestricted use, distribution, and reproduction in any medium, provided the original author and source are credited. 